\title{
Investigation and Research on the Psychological Capital State of New Students in Higher Vocational Colleges in the Post- pandemic Period
}

\author{
Ling Qiao
}

Sichuan Vocational College of Information Technology, Guangyuan Sichuan, 628017, China

\begin{abstract}
The investigation on the psychological capital state was conducted on 1200 new students of the class 2020 in the province, it was found that in the Post-pandemic period, the psychological capital of new students in higher educational colleges was generally good after experiencing a series of major life events, but still needed further improvement.
\end{abstract}

Keywords: Post-pandemic Period; Psychological Capital; State.

\section{Introduction}

On January 20, 2020, the COVID-19 epidemic broke out; pandemic endangered the public health security of the country and the world. After tight prevention and control, and then returning to normal social and economic life, we have entered the "Post-pandemic period", namely prevention and control have entered normalization, but the risk of pandemic rebound o still exists. College students in this period have experienced a series of major life events: pandemic, going back to school, college entrance examination, and entering a new school in just six months, whether they can successfully complete their college studies, what is their mental health state, for colleges and universities, how to accurately grasp their psychological needs, how to effectively prevent psychological crises in the Post-pandemic period, and conduct targeted mental health education are the primary tasks at present. This paper attempts to explore the psychological capital state of new students in higher educational colleges in the Post-pandemic period, and provide the corresponding basis for work in the future.

\section{Core Concept}

The concept of psychological capital is gradually developed from economics and organizational behavior, which is a state of positive psychological development. The psychological capital of college students is the sum of positive abilities possessed by college students in the special stage of life development, which can be developed and measured, and has relative stability, mainly including four dimensions: self-efficacy, optimism, hope and resiliency.

\section{Research Objectives}

Table 1. The sample distribution

\begin{tabular}{|c|c|c|c|}
\hline & category & sample size & percentage \\
\hline & boy student & 528 & $48.93 \%$ \\
\hline gender & girl student & 551 & $51.07 \%$ \\
\hline only child & yes & 324 & $30.03 \%$ \\
\hline student hometown & no & 155 & $69.97 \%$ \\
\hline & countryside & 877 & $81.28 \%$ \\
\hline & town & 202 & $18.72 \%$ \\
\hline
\end{tabular}

This paper sent out questionnaires to 2020 new students in Sichuan Vocational College of Information Technology, Sichuan Water Conservancy College, Sichuan Business Vocational College, Yibin Vocational \& Technical College, Ya'an Polytechnic College and other higher vocational 
Volume 3 (2021)

colleges in accordance with random sampling. 1200 questionnaires were sent out and 1079 valid questionnaires were collected, the recovery rate is $89.9 \%$. The sample distribution is as follows.

\section{Research Tool}

This investigation adopts the positive psychological capital questionnaire compiled by Zhang Kuo, et al. (2010), 7-point scoring method is used to obtain scores of each item, this questionnaire includes 26 items, which consists of hope, optimism, self-efficacy, resiliency, the self-efficacy and resiliency factors consisted of 7 items, respectively, and the optimism and hope factors consist of 6 items respectively. The questionnaire conducts seven 7 scoring of Likert scale. The sum of the scores of each factor reflects the psychological capital state of individuals, and higher scores show that individuals are richer in positive psychological capital. The Cronbach's $\alpha$ coefficient of the total scale is 0.90; and the Cronbach's acoefficients of various dimensions are 0.86, 0.83,0.80, and 0.76, respectively, and the questionnaire has good reliability and validity.

\section{Research Purpose}

Understanding the psychological capital state of new students in higher vocational colleges and its differences in the demographic variables: gender, student hometown, and whether they are only children; understanding whether it is related to family economic conditions, family upbringing, family structure, studies, and whether act as student leader.

\section{Research Results}

(1) Differences in psychological capital of freshmen in higher education in terms of gender

Table 2 Analysis of the differences in psychological capital of freshmen in higher education in terms of gender

(2) Differences in psychological capital of new students in higher vocational colleges in gender

Table 2. Analysis of the differences in psychological capital of new students in higher vocational colleges in gender

\begin{tabular}{|c|c|c|c|c|c|}
\hline & gender & $\mathrm{M}$ & $\mathrm{SD}$ & $\mathrm{t}$ & $\mathrm{P}$ \\
\hline \multirow{2}{*}{ positive psychological capital } & male & 4.66 & 0.83 & 5.97 & 0.00 \\
\cline { 2 - 6 } & female & 4.37 & 0.80 & & \\
\hline
\end{tabular}

Table 3. Correlation analysis of psychological capital of new students in higher vocational colleges in various dimensions of gender

\begin{tabular}{|c|c|c|c|c|c|}
\hline variable & 1 & 2 & 3 & 4 & 5 \\
\hline gender & 1 & & & & \\
\hline self-efficacy & $-.223^{* *}$ & 1 & & & \\
\hline resilience & $-.220^{* *}$ & $.445^{* *}$ & 1 & & \\
\hline hope & $-.087^{* *}$ & $.692^{* *}$ & $.401^{* *}$ & 1 & \\
\hline optimism & -.056 & $.622^{* *}$ & $.387^{* *}$ & $.702^{* *}$ & 1 \\
\hline positive psychological capital & $-.178^{* *}$ & $.847^{* *}$ & $.687^{* *}$ & $.866^{* *}$ & $.840^{* *}$ \\
\hline
\end{tabular}

Note: $* \mathrm{p}<0.05, * * \mathrm{p}<0.01, * * * \mathrm{p}<0.01$ (similarly hereinafter)

The results showed that the total scores of psychological capital of new students in higher vocational colleges are significantly different in genders. The total scores of psychological capital and scores of various dimensions of new students in higher vocational colleges are correlated with gender.

(3) Differences in psychological capital of new students in higher vocational colleges in whether they are only children or not 
Table 4. Analysis of the differences of psychological capital of new students in higher vocational colleges in whether they have only one child or not

\begin{tabular}{|c|c|c|c|c|c|}
\hline & only child & M & SD & t & P \\
\hline \multirow{2}{*}{ positive psychological capital } & yes & 4.54 & 0.80 & 0.63 & 0.55 \\
\cline { 2 - 6 } & no & 4.50 & 0.84 & & \\
\hline
\end{tabular}

The results show that there is no significant difference between the total scores of psychological capital of new students in higher vocational colleges whether they are only children or not.

Table 5. Correlation analysis of psychological capital of new students in higher vocational colleges whether they are only children or not

\begin{tabular}{|c|c|c|c|c|c|}
\hline variable & 1 & 2 & 3 & 4 & 5 \\
\hline whether they are only children or not & 1 & & & & \\
\hline self-efficacy & -.047 & 1 & & & \\
\hline resilience & -.022 & $.445^{* *}$ & 1 & & \\
\hline hope & -.021 & $.692^{* *}$ & $.401^{* *}$ & 1 & \\
\hline optimism & .028 & $.622^{* *}$ & $.387^{* *}$ & $.702^{* *}$ & 1 \\
\hline positive psychological capital & -.018 & $.847^{* *}$ & $.687^{* *}$ & $.866^{* *}$ & $.840^{* *}$ \\
\hline
\end{tabular}

The results show that there is no significant difference between the total psychological capital scores and the scores of various dimensions of new students in higher vocational colleges in whether they are only children or not. There is no correlation between the total scores of psychological capital and the scores of various dimensions of new students in higher vocational colleges and the only child.

(4) Correlation analysis between psychological capital of new students in higher vocational colleges and student hometown.

As shown in Table 6, the correlation analysis between the total scores of psychological capital and scores of various dimensions and the student hometown is conducted, and the results showed that there is a significant correlation between the total scores of psychological capital, scores of various dimensions and student hometown.

(5) Correlation analysis between psychological capital and family structure of new students in higher vocational colleges.

Table 6. Correlation analysis between psychological capital of new students in higher vocational colleges and student hometown

\begin{tabular}{|c|c|c|c|c|c|}
\hline variable & 1 & 2 & 3 & 4 & 5 \\
\hline Where are you from? & 1 & & & & \\
\hline self-efficacy & .098 & 1 & & & \\
\hline resilience & -.003 & $.445^{* *}$ & 1 & & \\
\hline hope & .052 & $.692^{* *}$ & $.401^{* *}$ & 1 & \\
\hline optimism & -.007 & $.622^{* *}$ & $.387^{* *}$ & $.702^{* *}$ & 1 \\
\hline positive psychological capital & .042 & $.847^{* *}$ & $.687^{* *}$ & $.866^{* *}$ & $.840^{* *}$ \\
\hline
\end{tabular}

Table 7. Correlation analysis of psychological capital of new students in higher vocational colleges

\begin{tabular}{|c|c|c|c|c|c|}
\hline \multicolumn{7}{|c|}{ in family structure } \\
\hline variable & 1 & 2 & 3 & 4 & 5 \\
\hline students' family structure & 1 & & & & \\
\hline self-efficacy & $-.075^{*}$ & 1 & & & \\
\hline resilience & $-.088^{* *}$ & $.445^{* *}$ & 1 & & \\
\hline hope & $-.080^{* *}$ & $.692^{* *}$ & $.401^{* *}$ & 1 & \\
\hline optimism & $-.083^{* *}$ & $.622^{* *}$ & $.387^{* *}$ & $.702^{* *}$ & 1 \\
\hline positive psychological capital & $-.100^{* *}$ & $.847^{* *}$ & $.687^{* *}$ & $.866^{* *}$ & $.840^{* *}$ \\
\hline
\end{tabular}


As shown in Table 7, the correlation analysis is conducted on the total scores of psychological capital and scores in various dimensions and the family structure, the results found that there is a significant correlation between the total scores of psychological capital, various dimensions and family structure.

(6) Correlation analysis of psychological capital of new students in higher vocational colleges and family educational methods.

Table 8. Correlation analysis of the psychological capital of new students in higher vocational colleges in the family educational methods

\begin{tabular}{|c|c|c|c|c|c|}
\hline variable & 1 & 2 & 3 & 4 & 5 \\
\hline educational methods & 1 & & & & \\
\hline self-efficacy & $-.104^{* *}$ & 1 & & & \\
\hline resilience & $-.092^{* *}$ & $.445^{* *}$ & 1 & & \\
\hline hope & $-.124^{* *}$ & $.692^{* *}$ & $.401^{* *}$ & 1 & \\
\hline optimism & $-.097^{* *}$ & $.622^{* *}$ & $.387^{* *}$ & $.702^{* *}$ & 1 \\
\hline positive psychological capital & $-.129^{* *}$ & $.847^{* *}$ & $.687^{* *}$ & $.866^{* *}$ & $.840^{* *}$ \\
\hline
\end{tabular}

As shown in Table 8, the correlation analysis is carried out on the total scores of psychological capital and the scores of various dimensions and the family education method, the results found that there is a significant correlation between the total scores of psychological capital and scores of various dimensions and the family educational method.

(7) Correlation analysis between psychological capital of new students in higher vocational colleges and family economic income

Table 9. Correlation analysis of psychological capital of new students in higher vocational colleges and family economic income

\begin{tabular}{|c|c|c|c|c|c|}
\hline variable & 1 & 2 & 3 & 4 & 5 \\
\hline family economic conditions & 1 & & & & \\
\hline self-efficacy & -.022 & 1 & & & \\
\hline resilience & -.042 & $.445^{* *}$ & 1 & & \\
\hline hope & $-.082^{* *}$ & $.692^{* *}$ & $.401^{* *}$ & 1 & \\
\hline optimism & -.049 & $.622^{* *}$ & $.387^{* *}$ & $.702^{* *}$ & 1 \\
\hline positive psychological capital & $-.061^{*}$ & $.847^{* *}$ & $.687^{* *}$ & $.866^{* *}$ & $.840^{* *}$ \\
\hline
\end{tabular}

As shown in Table 9, the correlation analysis is carried out on the total scores of psychological capital and the scores of various dimensions and the family economic income, the results found that there is a significant correlation between the total scores of psychological capital and scores of various dimensions and the family economic income.

(8) Correlation analysis of psychological capital and studies of new students in higher vocational colleges.

Table 10. Correlation analysis of psychological capital and studies of new students in higher vocational colleges

\begin{tabular}{|c|c|c|c|c|c|}
\hline variable & 1 & 2 & 3 & 4 & 5 \\
\hline studies & 1 & & & & \\
\hline self-efficacy & $-.253^{* *}$ & 1 & & & \\
\hline resilience & $-.134^{* *}$ & $.445^{* *}$ & 1 & & \\
\hline hope & $-.287^{* *}$ & $.692^{* *}$ & $.401^{* *}$ & 1 & \\
\hline optimism & $-.219^{* *}$ & $.622^{* *}$ & $.387^{* *}$ & $.702^{* *}$ & 1 \\
\hline positive psychological capital & $-.276^{* *}$ & $.847^{* *}$ & $.687^{* *}$ & $.866^{* *}$ & $.840^{* *}$ \\
\hline
\end{tabular}

As shown in Table 10, the correlation analysis is conducted on the total scores of psychological capital and the scores of various dimensions and studies, the results found that there is a significant 
correlation between the total scores of psychological capital and scores of various dimensions and studies.

(9) Correlation analysis of the psychological capital of new students in higher vocational colleges and whether act as class leader.

Table 11. Correlation analysis of the psychological capital of new students in higher vocational colleges and whether act as class leaders

\begin{tabular}{|c|c|c|c|c|c|}
\hline variable & 1 & 2 & 3 & 4 & 5 \\
\hline whether act as class leader & 1 & & & & \\
\hline self-efficacy & $-.207^{* *}$ & 1 & & & \\
\hline resilience & -.013 & $.445^{* *}$ & 1 & & \\
\hline hope & $-.093^{* *}$ & $.692^{* *}$ & $.401^{* *}$ & 1 & \\
\hline optimism & $-.063^{*}$ & $.622^{* *}$ & $.387^{* *}$ & $.702^{* *}$ & 1 \\
\hline positive psychological capital & $-.114^{* *}$ & $.847^{* *}$ & $.687^{* *}$ & $.866^{* *}$ & $.840^{* *}$ \\
\hline
\end{tabular}

As shown in Table 11, the correlation analysis is carried out on the total scores of psychological capital and the scores of various dimensions and whether act as class leader, the results found that there is a significant correlation between the total scores of psychological capital and scores of various dimensions and whether act as class leader.

\section{Summary and Suggestions}

\section{(1) Summary}

1). The overall situation of psychological capital of new students in higher vocational colleges is good. It was found that the overall situation of positive psychological capital of the class 2020 new students in higher vocational colleges is good via data analysis, and the psychological capital level of more than $80 \%$ of the students is higher than the theoretical median value 3.5 . However, it is not difficult to see from the data that the development of each factor is not balanced among the four factors of psychological capital. After experiencing a series of major life events, new students in higher vocational colleges show a high optimism level, but scores in hope, resilience and self-efficacy are low, this has a certain relationship with higher vocational students who have not been valued by family and school for a long time, lack self-confidence, and lack a correct understanding for themselves.

2). There is a significant difference in the psychological capital level between girl students and boy students. In overall psychological capital, the average value of boy students $(\mathrm{M}=4.66)$ is significantly higher than that of girl students $(M=4.37)$, it shows that the boy students' psychological capital level is significantly higher than that of girl students, and boy students have more positive psychological energy than girl students. In Chinese traditional culture, the expectations for men are generally masculine, responsible, and strong. The requirements for women are gentle, considerate, and kind, and do not require a stronger sense of competition. In social life, men's achievements are also more recognized, therefore, boys show more self-confidence for themselves, are more willing to work hard to achieve goals, are more willing to persist, and face challenges bravely, while girls are more willing to engage in simple tasks, and their optimism and expectations for the future are also weak.

3). The psychological capital of new students in higher vocational colleges is closely related to family factors. Various data show that the psychological capital of new students in higher vocational colleges is closely related to their family factors. Especially the family structure and educational methods have a greater impact on students. The survey results also show that the optimism level of students from single-parent families is significantly lower than that of two-parent families; the optimism level of students who grow up under democratic family educational methods is significantly higher than that of students who grow up under other family educational methods, all show that the family structure and educational methods have an important influence on the 
psychological capital of college students. Family economic income also has a certain impact on psychological capital. The family's financial situation is good, students are more likely to be satisfied with their material lives, and have optimistic expectations for the future, but they tend to lack fighting spirit and have less resilience; while families with poor economic situation, students are more pessimistic about the future, but have higher resilience.

4). School factors have a significant impact on the psychological capital of new students in higher vocational colleges. In the survey of "whether act as class leader", it can be seen that students who are class leaders show more confidence in daily work and study, that have higher self-esteem, are willing to engage in challenging tasks, and are full of hope for the future, they can face difficulties positively and are willing to persevere. This is because students who are class leaders can face more opportunities than other students, and can improve their social ability and status in various activities of the school and class, in the process of serving the students, in the active communication with the teachers. The excellent degree of studies at school can also help them improve their self-confidence, change the phenomenon that has not been valued by teachers and classmates for a long time, and find the positive side of life again.

(2) Suggestions

Improving the qualities of individual self-confidence, optimism, hope, and resilience is the gist of Marx on the requirements of the all-round development of human. Therefore, higher vocational colleges must establish and perfect system that can truly improve the psychological capital of students in higher vocational colleges, and integrate the improvement of psychological capital into the work of psychological health education. The schools must attach importance to college students' mental health education courses this the main channel of publicity and education, and systematically help students cultivate psychological capital; build a good campus environment, integrate implicit education into the cultivation of psychological capital, and make students be influenced and educated subtly; it is necessary to actively integrate the resources of various departments in the school, create a relaxed and pleasant campus environment, and create a good external environment for students to form a positive, optimistic, rational and peaceful attitude; it is necessary to strengthen home-school cooperation, guide parents to correctly face parent-child conflicts, and build effective communication; it is necessary to strengthen cooperation with psychiatric hospitals, open the diagnosis mechanism and professional diagnosis and consultation channels, and ensure timely and effective prevention and interventions for student crisis.

\section{Acknowledgments}

This paper is the phased result of the research project of the Education Department of Sichuan Province and the Sichuan University Mental Health Education Training Base, "Research on the Psychological Capital State of New Students in Higher Vocational Colleges and Improvement Paths in the Post-pandemic Period" (project number: 2020SXJP027).

\section{References}

[1] Cao Donghui. Investigation on the Psychological Capital State of Students in Higher Vocational Schools [D]. Shanxi Youth. 2020.5.

[2] Zhu Lifen, Pan Yashu, Zhou Xian. A Study on the Current Situation of Psychological Capital of College Students [J]. Journal of Kunming Metallurgy College, 2019 (3): 12-17.

[3] Xiao Jin, Sun Yiwa, Zhou Huixin, The Empirical Study on the Influence of Dormitory Interpersonal Relationship on College Students' Psychological Capital. Chinese Forest Education [J], 2013.4.

[4] Huang Hui. Research on the Correlation between Psychological Capital and Psychological Health of College Students [D]. Guangxi Normal University, 2011. 